\title{
Opinions on Kampo and reasons for using it - results from a cross-sectional survey in three Japanese clinics
}

Lydia Hottenbacher', Thorolf ER Weißhuhn ${ }^{1}$, Kenji Watanabe², Takashi Seki ${ }^{3}$, Julia Ostermann ${ }^{1}$ and Claudia M Witt ${ }^{1,4^{*}}$

\begin{abstract}
Background: Traditional Japanese Medicine (Kampo) is often used in Japan, but very little data on its users are available. We investigated who uses Kampo, the reasons and opinions for its use.

Methods: Questionnaire survey in three Japanese outpatient clinics offering Kampo in different settings: Kampo only, Kampo and traditional Chinese medicine, Kampo and Western medicine. Before seeing the doctor, patients were asked about socio-demographic data, medical history, experience with Kampo, general health-related opinions and behaviours, opinions about Western medicine and Kampo, and reasons for Kampo utilization. Descriptive statistics and predictors for Kampo use were calculated.

Results: A total of 354 questionnaires were completed. Participants were $50.97 \pm 15.60$ (mean \pm SD) years of age, $68 \%$ were female. Of all patients, $73 \%(n=202)$ were using Kampo currently and 84\% (297) had taken Kampo before. Questions on general health-related opinions and behaviour revealed a strong environmental awareness. The most frequent indications for earlier Kampo use were: common cold (36\%), gastrointestinal complaints (30\%), oversensitivity to cold ("Hi'e-sho"; 29\%), stress/anxiety (21\%), and shoulder stiffness (20\%). Kampo users suffered more often from chronic illnesses (OR 2.88 [1.48-5.58]). Beliefs in underlying philosophy (Wu Xing (adjusted OR 3.08, [1.11-8.55]), Ying and Yang (OR 2.57 [1.15-5.73], a holistic way of seeing the patient (OR 2.17 [1.53-3.08]), and in Kampo efficacy (OR 2.62 [1.66-4.13]) were positively associated with Kampo use. So was, interestingly, conviction of the efficacy of Western medicine (OR 1.87 [1.28-2.74]). Half of the patients had a general preference for a combination of Kampo and Western treatment.
\end{abstract}

Conclusions: Most patients visiting a clinic that also provided Kampo had previous experience with Kampo. Usage was associated with beliefs in philosophical Kampo concepts and its efficacy.

Keywords: Kampo, Survey, Patient opinions

\section{Background}

Complementary and alternative medicine (CAM) is increasingly used worldwide [1], especially in industrialized countries including Japan [2-4]. The CAM therapies most used in Japan in the general population during the last 12 months before a telephone survey were nutritional and tonic drinks as well as dietary supplements

\footnotetext{
* Correspondence: claudia.witt@charite.de

'Institute for Social Medicine, Epidemiology and Health Economics,

Charité University Medical Center, Berlin D-10098, Germany

${ }^{4}$ University of Maryland School of Medicine, Center for Integrative Medicine, Baltimore, USA

Full list of author information is available at the end of the article
}

(43.1\% each), Kampo (17.2\% over-the-counter plus $10.0 \%$ prescribed), health-related devices $(21.5 \%)$, massage or acupressure (14.8\%), and aromatherapy (9.3\%) [3]. Kampo (also: Kanpo, 漢方, or Kampo Igaku, 漢方医学) is a traditional medicine used almost solely by Japanese. Among those with diseases, it is the most popular CAM modality $[5,6]$.

Although rooted in Chinese tradition, Kampo medicine is not the same as Chinese medicine (CM). CM emphasizes the traditional concepts of East Asian natural philosophy, such as Yin and Yang or the theory of the Five Elements. Japanese Kampo favours diagnostic methods

\section{Biomed Central}


that directly relate symptoms to therapy, bypassing speculative concepts. The vast array of crude drugs has been reduced in Kampo and also the quantity of each drug in the formulation is much lower. While Kampo maintains traditional prescriptions, CM also tends to create new drug combinations [7,8]. A Kampo diagnosis (shô, 証; a kind of constitutional state [9]) is based on history taking, inspection (including tongue), smell, listening to body sounds, and palpation of pulse and abdomen [10]. The treatment (hô, 方) usually consists of herbal preparations. Animal or mineral preparations, acupuncture, or moxibustion are rarely applied $[11,12]$.

Kampo had been supplanted with the "medicine from the West" (seiyô igaku, 西洋医学), the Western biomedicine that is often referred to as "conventional" medicine in the Western world. Kampo was nearly nonexistent in the early $20^{\text {th }}$ century, but has seen a strong resurgence in popularity. Some examples shall illustrate this: Even before 1980 a colloquial term "kanpo boomu" [sic], "the Kampo boom", existed [13]. In 2005, Kampo was practiced by $78 \%$ of the doctors in Kyoto and was taught in all Japanese medical schools [14]. The 2009 annual Japanese expenditure on Kampo products reached about 1 billion USD, excluding over-the-counter (OTC) sales [15]. A review of clinical research on Kampo in 2011 identified 135 studies, which indicates a growing research interest [7]. A corresponding methodology to satisfy both Kampo and Western diagnostic systems has been developed [7]. Because it has been included in, or subordinated to, the Western health care system [16], (about $90 \%$ of its costs are now reimbursed by the national healthcare system), it has been tentatively suggested that Kampo is no longer an "alternative" or "complementary" medical system [17]. Nowadays a prescription is seldom based on the traditional shô diagnosis alone but used as co-medication for a Western-diagnosed (ICD-10) disease [18].

Although one out of ten Japanese is prescribed Kampo [3], very little data on its use and users are available. A small number of surveys have been performed in Kampo outpatient clinics [6,19-22]. Earlier works lacked usage data $[13,23,24]$, while in more recent surveys on the use of CAM Kampo was only listed as one of several treatment modalities but was not investigated in detail [3-5,25-28]. We therefore performed a survey to gain more insights into Kampo use. Especially the reasons why patients use it, what they think about it, and how they see it in relation to Western medicine were investigated in patients of three clinics that offer Kampo treatment. The term "Kampo" in this paper will include both the actual use of Kampo therapies as well as the decision for it (covering the whole range from a full shô diagnosis by an expert to an advertisement-induced layman's decision).

\section{Methods}

We performed a multicenter cross-sectional survey between $1^{\text {st }}$ September and $30^{\text {th }}$ October 2008 in three Japanese clinics that offer Kampo treatment. In this paper they will be labelled as follows:

- "Kampo": Outpatient clinic at a large private university hospital in Tokyo. Only Kampo is practiced (classically, i.e., based on a shô diagnosis).

- "Kampo/CM": Public university hospital in Sendai. Kampo is used primarily; in cases of insufficient improvement acupuncture and moxibustion from Chinese Medicine (CM) are used. Patients are almost always treated as outpatients, but 20 beds (out of 1000) are available for Kampo patients.

- "Integrative": The clinic of an internist in own practice in Sendai who practices Western medicine, Kampo among various other CAM therapies, as well as counselling.

The original survey included a fourth clinic that provided only Western medicine. This data has been presented in LH's thesis [29]. The present paper focuses on understanding Kampo users and includes only the Kampo providing clinics. In each clinic, either the clinic staff or one of the authors (LH) approached all patients who could expect at least half an hour waiting time. Participation was optional and anonymous. If the patients could not complete the questionnaire in time, they were asked to complete it after the consultation. No age restrictions applied; for children, the accompanying parent or guardian answered the questionnaire. If desired or needed (e.g. vision impairment), the questions were read to the patients and the answers written for them (by staff or LH). Patients whose physical or mental status made participation impossible were excluded.

The questionnaire had been newly developed in English in cooperation with epidemiologists, medical doctors, and Kampo specialists. A native speaker and $\mathrm{LH}$ translated it to Japanese; it was pretested and revised before it was applied. Its items included the following topics: demographics; medical history including serious illnesses in the last five years, current chronic, and any mental illnesses; diseases or symptoms that had initiated the consultation; some background to the current consultation; the patients' general preventive strategies; generally preferred therapies (Kampo, Western medicine, both combined). The previous use of Kampo (yes/no) defined the users/ non-users subgroups; users were asked for origin/prescriber and disease/symptom (free text). Patients were also asked for their estimation what the most useful treatment would be (Western medicine, Kampo, Western medicine + Kampo, don't know) for a list of 29 frequent diagnoses or symptoms. The list was based mostly on the works of 
Furnham [30], but modified for Japanese prevalence (16 diagnoses were left unchanged, 11 deleted from the list or subsumed under broader categories, 14 were added). Further items included the patients' experiences with Kampo, and other opinions (free-text comments). Also recorded was the degree of agreement (5-point Likert item, 1 = "I don't agree at all", 5 = "I totally agree") on general statements that covered the topics: health and health-related everyday behaviour; Western medicine and Kampo (perceived efficacy, satisfaction, estimation of side effects, philosophical background of Kampo); agreement on reasons for current use or non-use of Kampo. A self-rating of knowledge

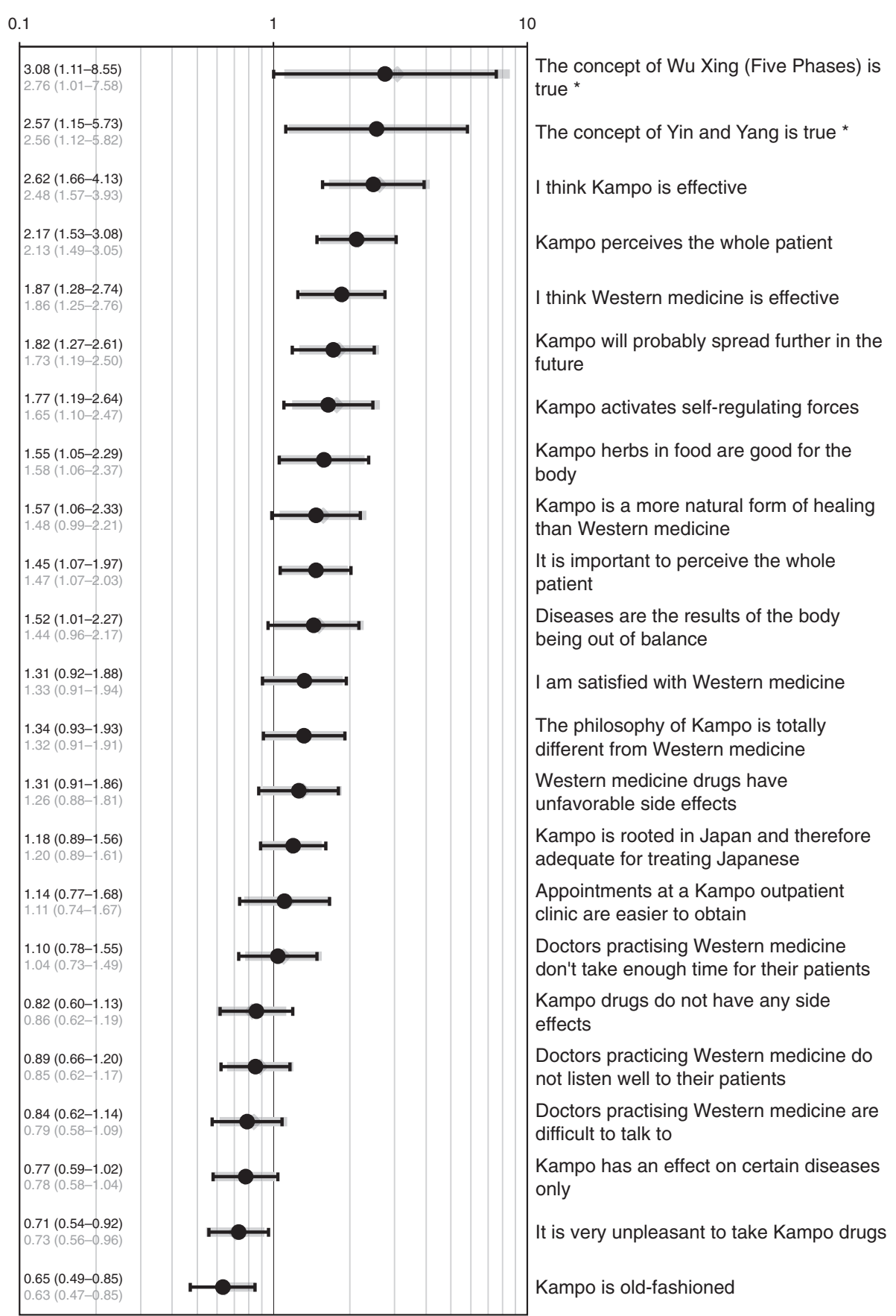

Figure 1 Opinions as predictors for Kampo use. Opinions on Kampo and Western medicine as predictors for Kampo use in a logistic regression model. Odds ratios with 95\% confidence interval, logarithmic scale. Black: adjusted for chronic disease (see text), grey: unadjusted.

* Only patients who knew about concept, broad Cl due to low number. "Western medicine" = "conventional" Western biomedicine. 
Table 1 Demographics and occupation

\begin{tabular}{|c|c|c|c|c|}
\hline Demographics & $\begin{array}{c}\text { All } \\
\%(n)\end{array}$ & $\begin{array}{c}\text { Kampo/CM } \\
\%(n)\end{array}$ & $\begin{array}{c}\text { Integrative } \\
\%(n)\end{array}$ & $\begin{array}{c}\text { Kampo } \\
\%(n)\end{array}$ \\
\hline Total * & $100.0(354)$ & $26.3(93)$ & $38.4(136)$ & $35.3(125)$ \\
\hline \multicolumn{5}{|l|}{ Sex } \\
\hline Female & $68.4(240)$ & $72.0(67)$ & $60.0(81)$ & $74.8(92)$ \\
\hline Male & $31.6(111)$ & $28.0(26)$ & $40.0(54)$ & $25.2(31)$ \\
\hline \multicolumn{5}{|l|}{ Age (years) } \\
\hline Mean \pm SD & $50.97 \pm 15.60$ & $57.46 \pm 15.92$ & $47.77 \pm 14.71$ & $49.62 \pm 14.99$ \\
\hline Range & $5-88$ & $14-88$ & $5-83$ & $22-77$ \\
\hline \multicolumn{5}{|l|}{ Education (Graduate) } \\
\hline Junior High School & $2.0(7)$ & $2.2(2)$ & $3.0(4)$ & $0.8(1)$ \\
\hline High School & $26.7(93)$ & $39.1(36)$ & $29.9(40)$ & $13.9(17)$ \\
\hline Beyond High School *** & $71.3(248)$ & $58.7(54)$ & $67.2(90)$ & $85.3(104)$ \\
\hline \multicolumn{5}{|l|}{ Marital Status } \\
\hline Single & $24.7(87)$ & $24.7(23)$ & $14.8(20)$ & $35.5(44)$ \\
\hline Married & $63.9(225)$ & $57.0(53)$ & $78.5(106)$ & $53.2(66)$ \\
\hline Divorced & $4.5(16)$ & $6.5(6)$ & $3.7(5)$ & $4.0(5)$ \\
\hline Widowed & $6.8(24)$ & $11.8(11)$ & $3.0(4)$ & $7.3(9)$ \\
\hline \multicolumn{5}{|l|}{ Occupational Situation } \\
\hline Employed & $47.1(160)$ & $34.1(31)$ & $56.8(75)$ & $46.2(54)$ \\
\hline Unemployed (Registered) & $2.4(8)$ & $1.1(1)$ & $3.8(5)$ & $1.7(2)$ \\
\hline Without Occupation **** & $27.6(94)$ & $31.9(29)$ & $23.5(31)$ & $29.1(34)$ \\
\hline Retired & $20.6(70)$ & $30.8(28)$ & $13.6(18)$ & $20.5(24)$ \\
\hline Attending School & $2.1(7)$ & $1.1(1)$ & $2.3(3)$ & $2.6(3)$ \\
\hline Retired Plus Working & $0.3(1)$ & $1.1(1)$ & $0.0(0)$ & $0.0(0)$ \\
\hline \multicolumn{5}{|l|}{ Type of Occupation ** } \\
\hline For a Firm & $54.7(98)$ & $46.7(21)$ & $61.3(46)$ & $52.5(31)$ \\
\hline For the Government & $11.2(20)$ & $13.3(6)$ & $13.3(10)$ & $6.8(4)$ \\
\hline Teaching & $8.4(15)$ & $8.9(4)$ & $9.3(7)$ & $6.8(4)$ \\
\hline Freelancer & $8.4(15)$ & $11.1(5)$ & $4.0(3)$ & $11.9(7)$ \\
\hline Self-Employed & $14.0(25)$ & $11.1(5)$ & $10.7(8)$ & $1.7(12)$ \\
\hline Entrepreneur & $3.4(6)$ & $8.9(4)$ & $1.3(1)$ & $0.8(1)$ \\
\hline \multicolumn{5}{|l|}{ Type of Employment ** } \\
\hline Regular & $68.6(116)$ & $74.4(29)$ & $72.7(56)$ & $58.5(31)$ \\
\hline Part Time/Side Job (arubeito) & $24.9(42)$ & $23.1(9)$ & $22.1(17)$ & $30.2(16)$ \\
\hline Interim Staffing & $5.3(9)$ & $0.0(0)$ & $25.2(4)$ & $9.4(5)$ \\
\hline Freelance & $0.6(1)$ & $2.6(1)$ & $0.0(0)$ & $0.0(0)$ \\
\hline Regular Plus Part Time & $0.6(1)$ & $0.0(0)$ & $0.0(0)$ & $1.9(1)$ \\
\hline \multicolumn{5}{|l|}{ Professional Duties ** } \\
\hline Management & $23.3(42)$ & $20.9(9)$ & $28.0(21)$ & $19.4(12)$ \\
\hline General Office Work & $43.3(78)$ & $51.2(22)$ & $38.7(29)$ & $43.5(27)$ \\
\hline Professional Job & $23.3(42)$ & $16.3(7)$ & $29.3(22)$ & $21.0(13)$ \\
\hline Other & $10.0(18)$ & $11.6(5)$ & $4.0(3)$ & $16.1(10)$ \\
\hline
\end{tabular}

Percent of valid answers, generally of clinic, ${ }^{*}$ of study population, ${ }^{* *}$ of respective group. ${ }^{* * *}$ Technical college, junior college/university, graduate school. ${ }^{* * * *}$ E.g., household. CM (traditional) Chinese medicine. 


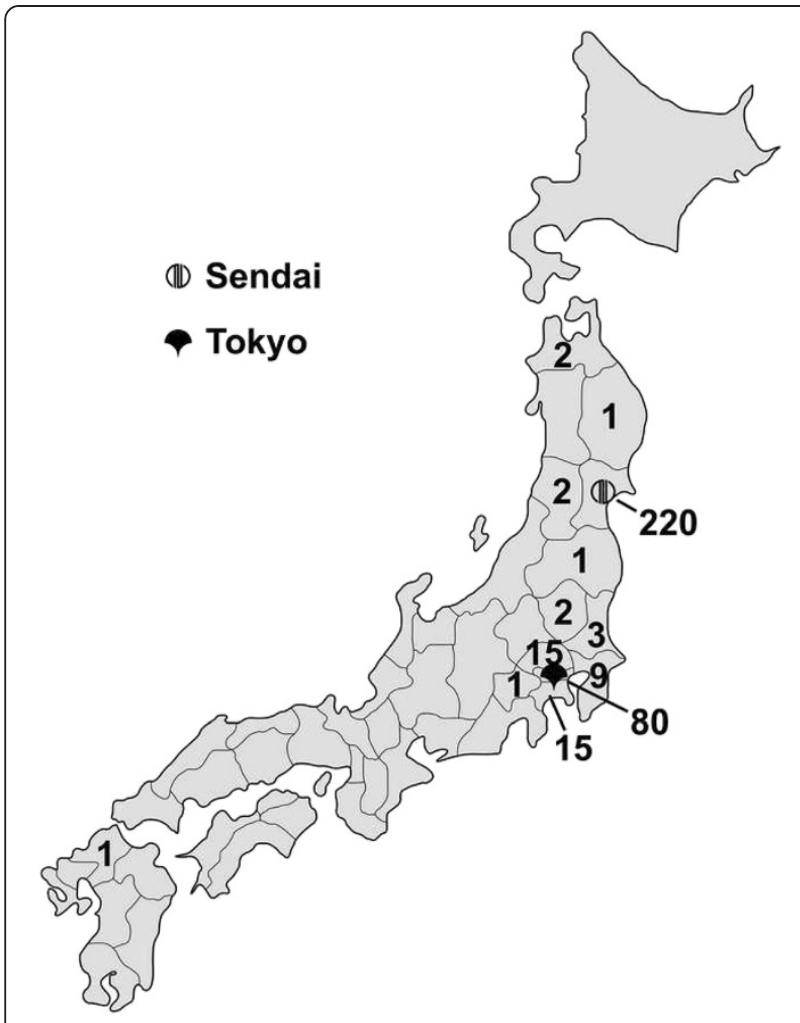

Figure 2 Study centres and patient residences. Number of patients from each prefecture. Map based on public domain material [31]. about Kampo diagnoses and treatment was recorded with a 5 -point Likert item ( $1=$ "No knowledge", $5=$ "Full knowledge").

For the total patient population, as well as for the subgroups from each clinic, and the Kampo users and non-users, we calculated descriptive statistics that included absolute and relative frequencies, and for parametric variables the mean and standard deviation (SD).
Free text answers were categorized. We used for test statistics non-parametric tests (Mann-Whitney U, KruskallWallis), and for discrete variables the Chi-square test. A first logistic regression analysis was performed to determine socio-demographic and medical aspects that predicted Kampo use (yes/no). The predictors used in this analysis included "type of clinic", "age", "gender" (female/ male), "married" (yes/no), "education" (high/low), "chronic disease" (yes/no), "mental illness" (yes/no) and "severe disease" (yes/no). The latter responses of categorical variables were used as references, respectively. The Wald test was used to test the statistical significance of each predictor in the model. In the model selection process, backward elimination was used for identifying the best predictors for Kampo use. The goodness-of-fit of the models was assessed based on a log-likelihood ratio test. The significant predictor of the selected model was included as an adjustment variable in several logistic regression analyses to determine the impact of attitudes or opinions about Kampo and Western medicine on predicting the use of Kampo. In each model a different predictor for Kampo use, based on an attitude or opinion about Kampo and Western medicine, was added (cf. Figure 1). The odds ratios (OR) and $95 \%$ confidence intervals $(\mathrm{CI})$ were calculated for both models. Missing data was left blank. Calculations were done with PASW Statistics 18 (all ${ }^{\circ}$ SPSS Inc.), and IBM SPSS Statistics 21 (' IBM Corp.). As an anonymous survey, our study did not require approval of an ethics committee.

\section{Results}

Of the 1,376 patients approached for the study, 354 (25.7\%) participated. Although the sample size in the different clinics was comparable, the percentage of participating patients varied: Kampo/CM clinic 73.2\% (93); Integrative clinic 52.1\% (136); Kampo clinic 12.7\% (125). More than two third of the patients completing the questionnaire were female (Table 1). Almost all patients $(98.0 \%)$ were at least high school graduates. Figure 2

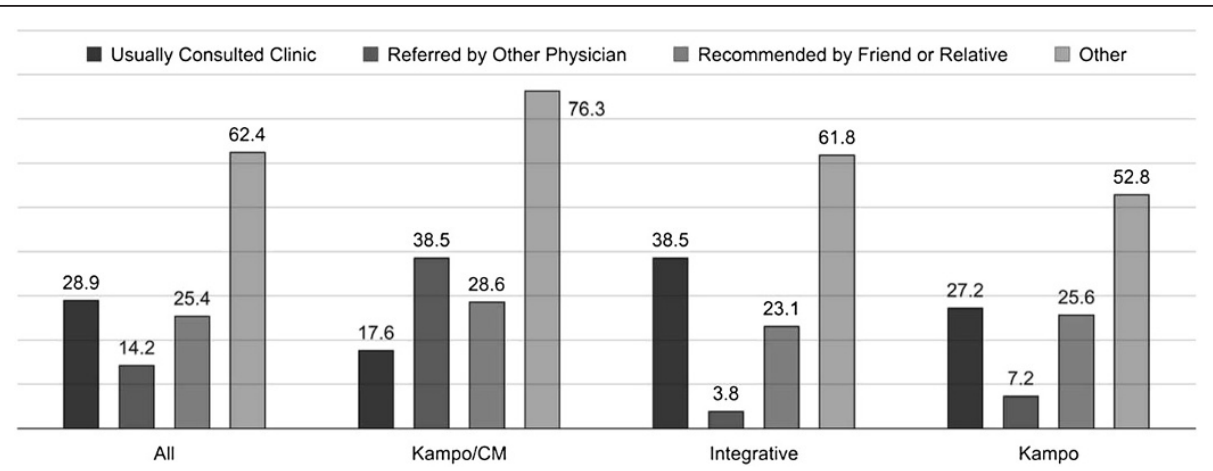

Figure 3 Reason for choosing study clinic. Percent of valid answers per clinic. CM (traditional) Chinese medicine. Free text answers (multiple answers possible) included media/internet $(n=40)$, the specific demand for Kampo (38), proximity (20), recommendations from friends or family (2), and other (41). 
shows that almost all patients came from the cities of the respective clinics Sendai $(62.5 \%$ of the study population, $\mathrm{n}=220)$ and Tokyo $(22.7 \%, 80)$, few came from the adjacent prefectures $(12.5 \%, 44)$. Why the clinic was chosen is shown in Figure 3.

Overall, 446 medical complaints (diseases or symptoms, 1.26 per patient) were stated as reasons for the current consultation. They had lasted for an average duration of $8.4 \pm 8.9$ (mean $\pm \mathrm{SD}$ ) years, varying between clinics (Kampo/CM 10.4 \pm 10.2 ; Integrative $6.3 \pm 7.7$; Kampo $8.8 \pm 8.6$ years). The most frequent complaints were classified as neurologic or psychiatric $(21.2 \%, \mathrm{n}=75)$, cardiovascular $(14.4 \%, 51)$, pain $(14.1 \%, 50)$, allergic or dermatological $(11.9 \%, 42)$, and gastroenterologic $(11.6 \%, 41)$ disorders. Half of the patients were chronically ill (50.6\% of valid answers, $\mathrm{n}=178$ ). They actually suffered from a total of 232 ailments, most frequently from cardiovascular $(11.3 \%, 40)$, neurological or psychiatrical $(8.2 \%, 29)$ or allergic/dermatological $(7.9 \%, 28)$ diseases. For the last 5 years before the survey 76 patients reported a total of 88 severe diseases (21.6\% of valid answers). The most frequent were gynaecological disorders $(4.5 \%, 16)$, neurologic or psychiatric disorders $(3.1 \%, 11)$, and gastroenterological $(2.8 \%, 10)$ disorders. (Details of diseases and symptoms are available in Additional file 1).
"Diet" $(37.3 \%, 132)$ and "Exercise" $(33.3 \%, 118)$ were the most often practised prevention strategies. As a general treatment preference, most patients wanted the combination of Kampo with Western medicine $(54.4 \%, 179)$, followed by Western medicine alone $(31.3 \%, 103)$. Kampo only was preferred by $14.3 \%$ (47) of the patients. From the provided list of 29 indications $\geq 30 \%$ of the patients regarded Kampo alone as best treatment option for 7 indications: Hi'e-sho, shoulder stiffness, digestive problems, allergy, stress or anxiety, hay fever, and disturbed sleep. Western medicine only was seen best only for pneumonia. For most indications $(n=25) \geq 30 \%$ of the patients favoured the combination of Kampo and Western medicine. (Percentages and values per clinic available in Additional file 1).

Questions on general health-related opinions and behaviour revealed a strong environmental awareness. Patients admitted to taking care for a healthy diet and actively seeking information about health issues (Table 2).

Of all participating patients, $73.2 \%$ (202) were currently using Kampo (Kampo/CM clinic 79.8\% (67); Integrative clinic 56.3\% (49); Kampo clinic 81.9\% (86)). Most patients (83.9\%, 297) had used Kampo before (Kampo/CM, 91.5\% (85); Kampo 88.0\% (110); Integrative $75.0 \%$ (102)), the last time $4.0 \pm 5.1$ (mean $\pm \mathrm{SD}$ ) years ago (Kampo/CM, $2.8 \pm 2.9$; Integrative $3.2 \pm 5.0$; Kampo $7.3 \pm 6.6$ ). Table 3

Table 2 Health-related opinions and behaviours

\begin{tabular}{|c|c|c|c|c|}
\hline \multirow[t]{2}{*}{ Statement } & \multirow{2}{*}{$\begin{array}{c}\text { All } \\
\text { Mean } \pm \text { SD } \\
\text { (Median) }\end{array}$} & \multirow{2}{*}{$\begin{array}{l}\text { Kampo/CM } \\
\text { Mean } \pm \text { SD } \\
\text { (Median) }\end{array}$} & \multirow{2}{*}{$\begin{array}{c}\text { Integrative } \\
\text { Mean } \pm \text { SD } \\
\text { (Median) }\end{array}$} & \multirow{2}{*}{$\begin{array}{c}\text { Kampo } \\
\text { Mean } \pm \text { SD } \\
\text { (Median) }\end{array}$} \\
\hline & & & & \\
\hline I think global warming is a priority issue & $4.05 \pm 1.04(4)$ & $4.12 \pm 1.02(4)$ & $3.93 \pm 1.01(4)$ & $4.13 \pm 1.07(4)$ \\
\hline $\begin{array}{l}\text { The government should spend more money on improvements } \\
\text { to the environment }\end{array}$ & $3.99 \pm 0.95(4)$ & $3.99 \pm 0.92(4)$ & $3.88 \pm 0.89(4)$ & $4.12 \pm 1.03(4)$ \\
\hline I try to avoid getting ill & $3.96 \pm 0.98(4)$ & $3.91 \pm 1.05(4)$ & $3.82 \pm 0.92(4)$ & $4.15 \pm 0.97(4)$ \\
\hline I keep an eye on the nutrition balance of my food & $3.95 \pm 1.01(4)$ & $4.10 \pm 1.00(4)$ & $3.67 \pm 1.04(4)$ & $4.14 \pm 0.91(4)$ \\
\hline I adjust my diet to suit my physical condition & $3.87 \pm 0.98(4)$ & $3.89 \pm 0.97(4)$ & $3.67 \pm 0.95(4)$ & $4.06 \pm 0.97(4)$ \\
\hline I read a lot about health in newspapers, books, magazines, etc. & $3.79 \pm 1.06(4)$ & $3.75 \pm 1.15(4)$ & $3.66 \pm 0.99(4)$ & $3.96 \pm 1.06(4)$ \\
\hline I pay attention to health information on TV and radio & $3.68 \pm 1.05(4)$ & $3.76 \pm 1.05(4)$ & $3.44 \pm 1.00(3)$ & $3.88 \pm 1.06(4)$ \\
\hline I don't eat food containing additives and preservatives & $3.62 \pm 1.09(4)$ & $3.70 \pm 1.11(4)$ & $3.39 \pm 1.03(3)$ & $3.82 \pm 1.09(4)$ \\
\hline $\begin{array}{l}\text { I think one should not take synthetic drugs for an extended period } \\
\text { of time }\end{array}$ & $3.62 \pm 1.06(3)$ & $3.58 \pm 1.10(3)$ & $3.42 \pm 0.99(3)$ & $3.87 \pm 1.08(4)$ \\
\hline I ask my doctor or pharmacist about the drugs prescribed to me & $3.60 \pm 1.06(4)$ & $3.65 \pm 1.01(4)$ & $3.44 \pm 0.97(3)$ & $3.75 \pm 1.16(4)$ \\
\hline $\begin{array}{l}\text { I ask my doctor or pharmacist about the side effects of the drugs } \\
\text { prescribed to me }\end{array}$ & $3.50 \pm 1.06(4)$ & $3.53 \pm 1.10(4)$ & $3.25 \pm 0.95$ (3) & $3.76 \pm 1.09(4)$ \\
\hline I buy organic food (organically produced vegetables, etc.) & $3.21 \pm 1.18(3)$ & $3.29 \pm 1.13(3)$ & $2.98 \pm 1.15(3)$ & $3.41 \pm 1.20(3)$ \\
\hline I exclude animal products from my food & $2.77 \pm 1.12(3)$ & $2.82 \pm 1.05(3)$ & $2.64 \pm 1.06(3)$ & $2.88 \pm 1.22(3)$ \\
\hline $\begin{array}{l}\text { When I see an ad about Kampo medicine I don't know, I ask my } \\
\text { doctor about it }\end{array}$ & $2.44 \pm 1.18(2)$ & $2.71 \pm 1.16(3)$ & $2.18 \pm 1.12(2)$ & $2.52 \pm 1.20(2)$ \\
\hline I pay attention to the lucky and unlucky days of the Buddhist calendar & $2.28 \pm 1.22(2)$ & $2.21 \pm 1.10(2)$ & $2.40 \pm 1.23(2)$ & $2.19 \pm 1.29(2)$ \\
\hline
\end{tabular}


Table 3 Indications for previous use of Kampo medicines

\begin{tabular}{|c|c|c|c|c|}
\hline Treated medical complaint & $\begin{array}{c}\text { All } \\
\%(n)\end{array}$ & $\begin{array}{c}\text { Kampo/CM } \\
\%(n)\end{array}$ & $\begin{array}{c}\text { Integrative } \\
\%(n)\end{array}$ & $\begin{array}{c}\text { Kampo } \\
\%(n)\end{array}$ \\
\hline Common Cold & $36.2(105)$ & $31.2(29)$ & $27.9(38)$ & $30.4(38)$ \\
\hline Gastrointestinal Complaints & $30.2(88)$ & $24.7(23)$ & $17.6(24)$ & $32.8(41)$ \\
\hline Hi'e-sho * & $29.0(84)$ & $31.2(29)$ & $12.5(17)$ & $30.4(38)$ \\
\hline Stress/Anxiety Disorder & $20.7(60)$ & $19.4(18)$ & $15.4(21)$ & $16.8(21)$ \\
\hline Shoulder Stiffness & $20.3(59)$ & $25.8(24)$ & $9.6(13)$ & $17.6(22)$ \\
\hline Gynaecological Disease & $18.2(53)$ & $14.0(13)$ & $13.2(18)$ & $17.6(22)$ \\
\hline Allergy & $16.8(49)$ & $11.8(11)$ & $7.4(16)$ & $17.6(22)$ \\
\hline Hay Fever & $14.8(43)$ & $16.1(15)$ & $8.1(11)$ & $13.6(17)$ \\
\hline Headache/Migraine & $13.1(38)$ & $17.2(16)$ & $8.8(12)$ & $8.0(10)$ \\
\hline Disturbed Sleep & $12.0(35)$ & $10.8(10)$ & $8.8(12)$ & $10.4(13)$ \\
\hline Low Back Pain & $11.0(32)$ & $12.9(12)$ & $2.9(4)$ & $12.8(16)$ \\
\hline Dermatological Disease & $9.7(28)$ & $7.5(7)$ & $0.7(1)$ & $16.0(20)$ \\
\hline Bronchitis & $6.9(20)$ & $4.3(4)$ & $5.9(8)$ & $6.4(8)$ \\
\hline Asthma & $6.5(19)$ & $8.6(8)$ & $3.7(5)$ & $4.8(6)$ \\
\hline Cystitis & $6.2(18)$ & $6.5(6)$ & $3.7(5)$ & $5.6(7)$ \\
\hline Muscular Disease & $6.2(18)$ & $8.6(8)$ & $2.9(4)$ & $4.8(6)$ \\
\hline Neuralgia & $5.5(16)$ & $7.5(7)$ & $2.9(4)$ & $4.0(5)$ \\
\hline Anaemia & $4.5(13)$ & $5.4(5)$ & $4.4(6)$ & $1.6(2)$ \\
\hline Depression & $4.5(13)$ & $2.2(2)$ & $4.4(6)$ & $4.0(5)$ \\
\hline Hypertension & $3.8(11)$ & $3.2(3)$ & $3.7(5)$ & $2.4(3)$ \\
\hline Kidney Disease & $3.4(10)$ & $3.2(3)$ & $0.7(1)$ & $4.8(6)$ \\
\hline Hypotension & $3.1(9)$ & $3.2(3)$ & $1.5(2)$ & $3.2(4)$ \\
\hline Obesity & $3.1(9)$ & $2.2(2)$ & $2.9(4)$ & $2.4(3)$ \\
\hline Rheumatic Disease & $2.7(8)$ & $3.2(3)$ & $2.2(3)$ & $1.6(2)$ \\
\hline Cancer & $1.7(5)$ & $1.1(1)$ & $0.0(0)$ & $3.2(4)$ \\
\hline Diabetes & $1.7(5)$ & $1.1(1)$ & $0.7(1)$ & $2.4(3)$ \\
\hline Gastric Ulcer & $1.7(5)$ & $1.1(1)$ & $0.7(1)$ & $2.4(3)$ \\
\hline Pneumonia & $1.7(5)$ & $2.2(2)$ & $0.7(1)$ & $1.6(2)$ \\
\hline Addiction (Alcohol, Drugs, Other) & $0.3(1)$ & $1.1(1)$ & $0.0(0)$ & $0.0(0)$ \\
\hline
\end{tabular}

Ailments for which Kampo had been used in the past. Percent of valid answers of Kampo users. CM (traditional) Chinese medicine. * Oversensitivity to cold syndrome, see text.

lists the most frequent medical complaints for which Kampo had been used then. One third (38.6\%) of the respective Kampo medication had not been prescribed or recommended by a health care professional (Figure 4). Most $(88.8 \%, 158)$ of the chronically ill had experience with Kampo.

The current use or non-use of Kampo was strongly based on the actual need and its attributed holistic and natural qualities (Table 4). It was seen as more effective and causing fewer side effects than Western treatment. Patients who did not use Kampo currently were open for future use (Table 4).

The opinions about Kampo and Western medicine valued it as a holistic, body harmonizing treatment, and as a stimulant for self-healing that was considered more natural than Western medicine but similarly effective. Those who knew the philosophical concepts of Yin-Yang and Wu Xing (Five Phases) saw them as valid. Generally, patients saw Kampo more suitable for the Japanese. Western medicine was seen as efficacious, but its physicians were seen to have less time, listen less well and were more difficult to consult. (Statements as in Figure 1, agreement data available in Additional file 1).

The predictor that best described Kampo use selected by backward elimination was found to be "chronic diseases" (OR 2.88 [1.48-5.58], $\mathrm{p}=0.002$ ). Age, severe diseases, type of clinic, education, mental illness, marital status, and gender could be excluded as predictors from 


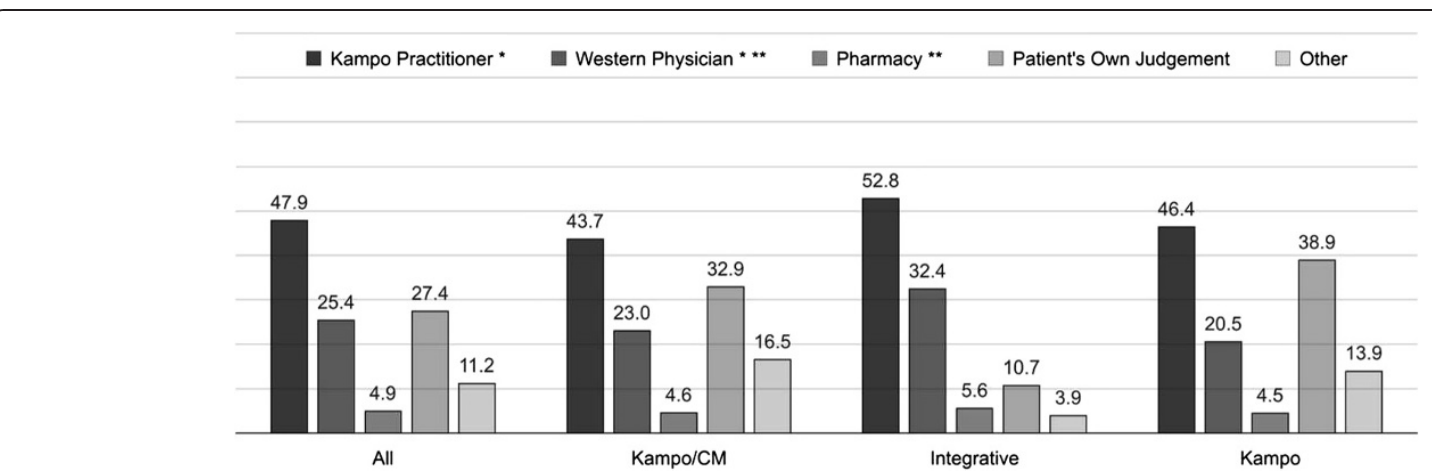

Figure 4 Who selected the Kampo medication in previous use. Multiple answers possible. Percent of valid answers per clinic. * Prescription, ${ }^{* *}$ Recommendation. CM (traditional) Chinese medicine.

the final model due to their minimal contribution to the model outcome. In short, patients who had used Kampo before and were treated in a Kampo-affine clinic suffered more often from chronic diseases than the non-users. Therefore, the presence of "chronic diseases" was used as the only adjustment variable to investigate the influence of opinions on Kampo and Western medicine for Kampo use. The resulting predictors for Kampo use (Figure 1) showed a positive association of Kampo use with beliefs in the underlying philosophy (Wu Xing (adjusted OR 3.08, [1.11-8.55]), Ying and Yang (OR 2.57 [1.15-5.73]), a holistic way of seeing the patient (OR 2.17 [1.53-3.08]), and in Kampo efficacy (OR 2.62 [1.66-4.13]. Interestingly, conviction of the efficacy of Western medicine (OR 1.87 [1.28-2.74]) also predicted for Kampo use.

Overall, the patients' self-rated knowledge about Kampo can be described as moderate (Figure 5). The means \pm SD ranged between clinics from $2.31 \pm 0.85$ (Integrative clinic) to $2.92 \pm 0.89$ (Kampo clinic), i.e., between $2=$ "not much knowledge" and $3=$ "normal knowledge".

\section{Discussion}

In our survey at three settings that were typical for Japanese health care and offering Kampo, the responding patients were predominantly female and of somewhat aboveaverage education. Most had used Kampo before. Their opinions were informed by convictions that could be described as "green" or "alternative", by a sense of responsibility for one's own health, and by the combination of philosophical concepts of Kampo with a pragmatic approach towards the choice of treatment (Western, Kampo, or both). The use of Kampo was positively associated with the presence of chronic diseases, the attribution of efficacy for both Kampo and Western treatments, the conviction of its natural or holistic qualities, and for some patients, the belief in specific Asian philosophies.

Among the strengths of the study are the diversity of the three clinics (representing different situations and intensities of Kampo usage, and thus, patient populations), the sample size, the inclusion of patients from all socioeconomic classes, and the modification of questionnaires from prior studies $[30,32]$ to better accommodate cultural aspects. Balancing the level of detail with feasibility we decided for a 5-point scale. Free text fields allowed getting more details, which in the highly normative Japanese culture constituted an enormous advantage. The included clinics represent typical settings of Japanese routine care that (including Kampo) is mostly provided by outpatient departments (gairai, 外来). An increasing number of universities offer Kampo [33], and patients prefer larger and more prestigious clinics [34]. We had therefore searched for larger outpatient clinics with a focus on Kampo that were also easily accessible for the general population, and, if possible, university clinics. The inclusion of a doctor in his own practice also covered another frequent setting.

The limitations include a possible recall bias, and a low response rate at one site (Kampo clinic). It certainly increased the response rate that clinic staff or one of the authors (LH) approached eligible patients personally. This was not possible in the Kampo clinic, where the small size of the waiting room, too, may have lowered the return rate. Results are certainly influenced by different clinic settings; for example, the long waiting period in the Kampo/Chinese medicine (Kampo/CM) clinic may have selected a different type of patients than the Integrative clinic with its shorter waiting time. A further setting-induced limitation is the exclusion of healthy citizens. They might have differed in their opinions, but would probably have been less interested in medical issues. We also did not expect our population to use Kampo for preventative purposes. Our study cannot claim representativity for Japanese health care; the more rural areas in particular were not represented. Disease prevalence and Kampo use are also likely to vary with the marked climatic change during the year, and the climatic differences across Japan are large but very small 
Table 4 Reasons for current Kampo use or non-use

\begin{tabular}{|c|c|c|c|c|}
\hline \multirow[t]{2}{*}{ Reasons } & \multirow{2}{*}{$\begin{array}{c}\text { All } \\
\text { lean } \pm \text { SD } \\
\text { (Median) }\end{array}$} & \multirow{2}{*}{$\begin{array}{c}\text { Kampo/CM } \\
\text { Mean } \pm \text { SD } \\
\text { (Median) }\end{array}$} & \multirow{2}{*}{$\begin{array}{c}\text { Integrative } \\
\text { Mean } \pm \text { SD } \\
\text { (Median) }\end{array}$} & \multirow{2}{*}{$\begin{array}{c}\text { Kampo } \\
\text { Mean } \pm \text { SD } \\
\text { (Median) }\end{array}$} \\
\hline & & & & \\
\hline \multicolumn{5}{|l|}{ For Using Kampo } \\
\hline Because I believe that Kampo is more holistic & $4.15 \pm 0.89(4)$ & $4.27 \pm 0.91(5)$ & $3.56 \pm 0.77(3)$ & $4.43 \pm 0.77(5)$ \\
\hline Because Kampo treatment is more natural & $4.08 \pm 0.90(4)$ & $4.14 \pm 0.97(4)$ & $3.77 \pm 0.82(4)$ & $4.23 \pm 0.86(4)$ \\
\hline Because my doctor suggested it to me & $3.86 \pm 1.43(4)$ & $4.08 \pm 1.29(5)$ & $4.31 \pm 1.06(5)$ & $3.38 \pm 1.62(4)$ \\
\hline $\begin{array}{l}\text { Because Kampo is more effective for my problem than Western } \\
\text { medicine }\end{array}$ & $3.88 \pm 0.96(4)$ & $4.10 \pm 0.91(4)$ & $3.49 \pm 0.88(3)$ & $3.97 \pm 0.98(4)$ \\
\hline Because Kampo has fewer side effects & $3.84 \pm 0.99(4)$ & $3.86 \pm 1.09(4)$ & $3.80 \pm 0.96(4)$ & $3.86 \pm 0.96(4)$ \\
\hline $\begin{array}{l}\text { Kampo offers a better explanation for my disease than Western } \\
\text { medicine }\end{array}$ & $3.58 \pm 1.46(3)$ & $3.87 \pm 1.14(4)$ & $2.94 \pm 1.03(3)$ & $3.80 \pm 0.99(4)$ \\
\hline $\begin{array}{l}\text { Because I am disappointed with Western medicine and want to try } \\
\text { something else }\end{array}$ & $3.05 \pm 1.46(3)$ & $3.12 \pm 1.53(3)$ & $2.37 \pm 1.30(2)$ & $3.44 \pm 1.37(4)$ \\
\hline $\begin{array}{l}\text { Because there is no treatment in Western medicine for my particular } \\
\text { disease }\end{array}$ & $2.93 \pm 1.41(3)$ & $3.12 \pm 1.41(3)$ & $2.30 \pm 1.07(3)$ & $3.23 \pm 1.48(3)$ \\
\hline Because someone apart from my doctor suggested it (family, friend) & $2.63 \pm 1.59(2)$ & $2.50 \pm 1.84(2)$ & $2.52 \pm 1.33(3)$ & $2.79 \pm 1.55(3)$ \\
\hline $\begin{array}{l}\text { Because the Western treatment I have received before was } \\
\text { distressing }\end{array}$ & $2.61 \pm 1.35(3)$ & $2.60 \pm 1.27(3)$ & $2.36 \pm 1.32(2)$ & $2.78 \pm 1.41(3)$ \\
\hline $\begin{array}{l}\text { Because treating my illness with Kampo is less expensive than } \\
\text { Western medicine }\end{array}$ & $2.40 \pm 1.04(3)$ & $2.43 \pm 1.02(3)$ & $2.68 \pm 0.93(3)$ & $2.19 \pm 1.08(2)$ \\
\hline \multicolumn{5}{|l|}{ For Not Using Kampo } \\
\hline I do not need it right now but would use it in the future if necessary & $4.02 \pm 1.01(4)$ & $3.78 \pm 1.39(4)$ & $4.02 \pm 0.94(4)$ & $4.50 \pm 1.00(5)$ \\
\hline Kampo is too expensive & $2.94 \pm 1.07(3)$ & $2.75 \pm 1.04(3)$ & $2.96 \pm 1.05(3)$ & $3.00 \pm 1.63(3)$ \\
\hline Taking Kampo medication is inconvenient & $2.76 \pm 1.19(3)$ & $2.00 \pm 1.31(1.5)$ & $2.92 \pm 1.09(3)$ & $2.40 \pm 1.67(2)$ \\
\hline Western medicine is very effective so that I do not need Kampo & $2.37 \pm 1.11(3)$ & $1.63 \pm 0.92(1)$ & $2.56 \pm 1.09(3)$ & $1.60 \pm 0.89(1)$ \\
\hline I think Kampo is not effective & $2.22 \pm 1.27(2)$ & $2.67 \pm 2.55(2)$ & $2.22 \pm 0.92(2)$ & $1.40 \pm 0.89(1)$ \\
\hline I was disappointed when using Kampo before & $1.87 \pm 0.99(1.5)$ & $1.63 \pm 1.19(1)$ & $1.94 \pm 0.98$ (2) & $1.50 \pm 1.00(1)$ \\
\hline
\end{tabular}

Answers on 5 point Likert item, 1 = "I fully disagree", 5 = "I fully agree", SD standard deviation. CM (traditional) Chinese medicine, "Western medicine" = "conventional" Western biomedicine.

between Sendai and Tokyo [35]. The limitations may explain the difference between our results $(83.9 \%$ of patients had used Kampo before) and general populationbased surveys, where a lifetime utilization of 37.5\% [5] of Kampo, or a 12-months prevalence of prescription Kampo of $10.0 \%$ [3] have been observed.
The majority of participating patients in the clinics offering Kampo were female, similar to another study at a Kampo clinic [21] including $68.4 \%$ women. However, in a population-based survey [3], no significant gender predominance was found in the subgroup of Kampo using patients. Almost all patients in our survey had

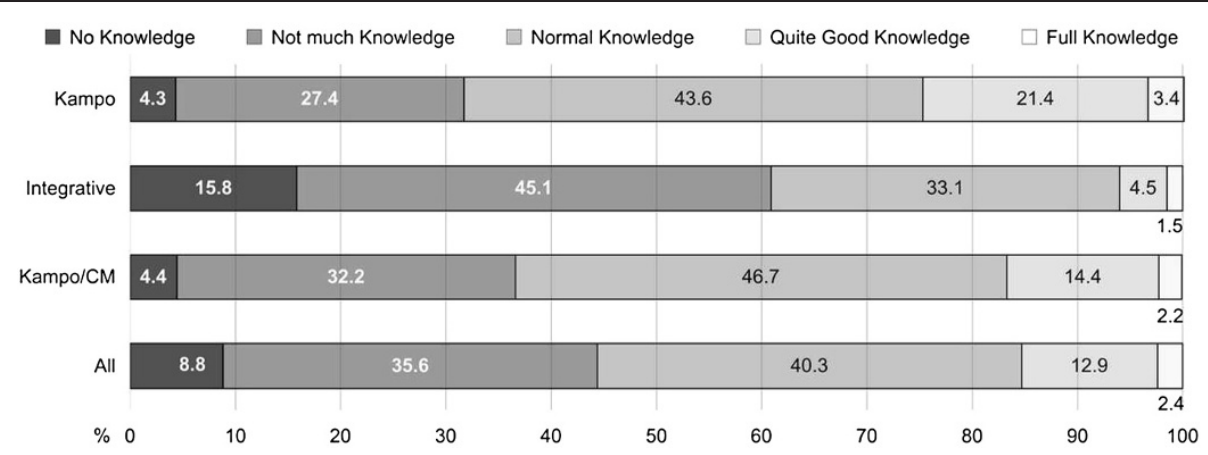

Figure 5 Kampo knowledge. Patients' self-rating of their knowledge. Percent of valid answers per clinic. CM (traditional) Chinese medicine. 
completed high school, in comparison to the Japanese census of 2000 (24.6\%) [36]. Costs were unlikely to have caused the difference, because prescription Kampo is almost fully reimbursed within the Japanese health insurance system. One explanation might be the metropolitan sample of the survey. The occupational situation was comparable to the general population [37] with the exception of a lower unemployment rate of $2.4 \%$ we observed (compared to about $4 \%$ in the survey period) [38]. This might result from our older, and thus for a greater part retired sample group, that in turn is caused by our inclusion of only diseased persons. Kampo is almost solely used in Japan, but our study showed results similar to international research on CAM in general: The patients were predominantly middle-aged, female, and higher educated $[39,40]$ and used CAM in addition to Western medicine [41].

Although Kampo with its holistic philosophy theoretically offers treatments for most medical complaints we found that it was used only for a limited spectrum of diseases. Recommendations for its sole use were only for medical complaints of a less serious nature for which Western medicine sometimes does not offer concepts or satisfying treatments. That diseases and symptoms varied between clinics might be due to demographic variations or clinic specializations. The results from our "Kampo" clinic differed from the results of an earlier survey at the same clinic, when most frequently diseases had been categorized as gynaecological, (23.2\%), dermatological, (17.1\%), and gastroenterological (15.2\%) [19]; the reason for the difference is unclear. Generally, we found that Kampo is used to a lesser extent for muscular diseases. Tradition may have informed public opinion in such a way that for musculo-skeletal problems acupuncture or osteopathy are regarded as best, and Kampo for internistic diseases. The "Hi'e-sho" (commonly 冷え性, experts prefer 冷え症) listed under the diagnoses or symptoms is an "oversensitivity to cold (syndrome)" quite common in Japan [42].

Not every patient was currently taking Kampo. Especially in the Kampo clinic, a high rate of new patients who were yet to receive their prescription answered the questionnaire. Generally, the current Kampo use may have been reduced by available treatment alternatives, especially in the Kampo/CM clinic where patients were also treated with acupuncture and/or moxibustion (without receiving Kampo), and in the Integrative clinic where even more alternatives existed.

In our study, a few less patients (27\%) had previously taken Kampo on their own decision (i.e., OTC) than in a survey from 1993 (33\%) [21]. Most had used it then after a recommendation by friends (42\%), some followed a physician's recommendation (16\%), and 6\% of the 198 patients because of media reports (TV, newspaper) [21].
The differences are likely due to Kampo becoming integrated into the medical mainstream (shifting weight from OTC to prescription), to changes in the media landscape (the Internet is likely to have caused much of the difference), as well as to differences in study centres, questionnaires and data acquisition. A study in 2002 [4] found that $19 \%$ of patients at a Tokyo general outpatient clinic had used Kampo in the last 12 months.

The stated reasons (musculo-skeletal problems, 15\%; gynaecological problems, 13\%; less or no side effects, $11 \%)$ differed again from our study, likely because of the different questionnaires used. Less perceived side effects was also a reason for using Kampo in 1992 [22]. Disappointment with Western medicine as such was not stated in 1980 [13] and also not seen as a reason by our patients (Kampo users even rated Western medicine more effective than non-users did). The East Asian worldviews that were found to be associated with its use in 1980 [13] seem to have prevailed. So did the notion that Kampo was more a complement to and not a mutually exclusive alternative to Western medicine [13]. We saw it, for example, in the high preference for the combination treatment. It is also reflected in the most frequently stated reasons for the use of CAM in general in Japan as found by others (Kampo being the most wanted, by $69 \%$ of the participating patients): treatment under physician's guidance, 55\%; coverage by health insurance, 49\%; Western medicine and CAM in same hospital, 47\%; higher effect from combining Western medicine and CAM, 43\%; multiple approaches, 42\% [5]. As seen in 1980, [13] we found that Kampo is used among all social strata and for a broad range of diseases.

Why a higher estimation of effectiveness for both types of medicines predicted for Kampo use is unclear. Perhaps a stronger sense of control over one's health (as seen in the opinion and prevention parts of the answers) correlates with the openness for treatment alternatives. The opinions on Kampo and the reasons for its use pointed to an inclination towards a certain degree of a "green" or "alternative" worldview. The perceived qualities of Kampo are likely to come from two sources. Satisfying experiences in the past certainly informed the current treatment recommendations, especially when conditions improved that did not get better under Western treatment (or even worsened), as found in a recent study [43]. Secondly, patients' identification with their choice of treatment [44] may play a not so small role. The moderate knowledge about Kampo and the emphasis on effectiveness suggests that choosing Kampo is less a matter of strong adherence to a theory or worldview than of pragmatism. This is consistent with the wide use and the large number of recommendations for a combination of Kampo and Western medicine. Together with the other results, these show that the 
investigated population perceives prescribed Kampo as an integrative part of Japanese health care, with particular strengths and limitations.

\section{Conclusions}

Most patients visiting a clinic that provided Kampo had previous experience with Kampo. Behaviour and opinions revealed a mindset with environmental awareness and philosophical reasoning, and a feeling of responsibility for one's own health. Kampo was used mostly for less serious diseases, and was seen by our population as an integrative part of the health care. Usage was associated with beliefs in philosophical Kampo concepts and its efficacy.

\section{Additional file}

Additional file 1: Additional detailed data (4 tables).

\section{Competing interests}

The authors declare that they have no competing interests.

\section{Authors' contributions}

CMW and LH developed the study idea; CMW supervised the study and data interpretation. $\mathrm{LH}, \mathrm{CMW}, \mathrm{KW}$, and TS developed the questionnaire and decided on the setting for the survey. LH was responsible for data acquisition, entry, and analyses; JO calculated the regression analysis and supervised LH data analyses. CMW, LH, KW, TS, JO and TW interpreted the data. LH, TW, CMW drafted the manuscript; all authors revised the manuscript. All authors read and approved the final manuscript.

\section{Acknowledgements}

Dr. Yasuo Tannou opened his clinic for the survey and helped on many other occasions. Prof. Hirohiko Azuma, Prof. Hisataka Moriwaki, Dr. Tomohiro Kato, and Dr. Hiroshi Araki supported LH work during her stay in Japan. Kiyomi Ikenaga assisted in developing and translating the questionnaire, and gave valuable advice when deciphering the patients' handwritten remarks. The research was supported by a travel grant from the German Academic Exchange Service (DAAD) and we thank Prof. Büchsel and the staff of the Tokyo DAAD office for on-site support. We thank Angelina Bockelbrink for her methodological support, Katja Icke for data management supervision and Iris Bartsch and Daniela Hacke for helping with the literature search. Furthermore, we thank the participating patients for their time and diligence.

\section{Author details}

${ }^{1}$ Institute for Social Medicine, Epidemiology and Health Economics, Charité University Medical Center, Berlin D-10098, Germany. ${ }^{2}$ Center for Kampo Medicine, Keio University School of Medicine, 35 Shinano-machi, Shinjuku-ku, Tokyo 160-8582, Japan. ${ }^{3}$ Department of Geriatric Behavioral Neurology, Tohoku University Graduate School of Medicine, 1-1 Seiryo-machi, Aoba-ku, Sendai 980-8575, Japan. ${ }^{4}$ University of Maryland School of Medicine, Center for Integrative Medicine, Baltimore, USA.

Received: 4 December 2011 Accepted: 9 May 2013 Published: 16 May 2013

\section{References}

1. Bodeker G, Ong CK, Grundy C, Burford G, Shein K: WHO global atlas of traditional, complementary and alternative medicine, Text volume. Kobe, Japan: World Health Organization, Centre for Health Development; 2005.

2. Roh PU: Regional overview: western pacific region. In WHO global atlas of traditional, complementary and alternative medicine. Text Volume. Edited by Ong C, Bodeker G, Grundy C, Burford G, Shein K. Kobe, Japan: World Health Organization, Centre for Health Development; 2005.
3. Yamashita H, Tsukayama H, Sugishita C: Popularity of complementary and alternative medicine in Japan: a telephone survey. Complement Ther Med 2002, 10(2):84-93.

4. Hori S, Mihaylov I, Vasconcelos JC, McCoubrie M: Patterns of complementary and alternative medicine use amongst outpatients in Tokyo, Japan. BMC Complement Altern Med 2008, 8:14.

5. Togo T, Urata S, Sawazaki K: Demand for CAM practice at hospitals in Japan: a population survey in Mie prefecture. eCAM 2011, Volume 2011 (Article ID 591868). doi:10.1093/ecam/neq049.

6. Uemura $\mathrm{H}$ : Heterogeneity among complementary and alternative therapies: results of a survey of outpatients in Japanese general practices. J Kyoto Prefectural Univ Med 2004, 113(5):285-294.

7. Watanabe K, Matsuura K, Gao P, Hottenbacher L, Tokunaga H, Nishimura K, Imazu Y, Reissenweber H, Witt CM: Traditional Japanese Kampo medicine: clinical research between modernity and traditional medicine: the state of research and methodological suggestions for the future. ECAM 2011, 513842(513841-513819). doi:10.1093/ecam/neq067.

8. Ishibashi A, Kosato H, Ohno S, Sakaguchi H, Yamada T, Matsuda K: General introduction to kampo. In Introduction to kampo. Edited by Sato Y, Arai M Cyong J, Fukuzawa M, Mitani K, Ogihara Y, Sakiyama T, Shimada Y, Toriizuka K, Yamada T. Tokyo: Elsevier; 2005:2-15.

9. Plotnikoff G, Watanabe K, Yashiro F: Kampo: from old wisdom comes new knowledge. HerbalGram 2008, 78:46-57.

10. Otsuka K: Kanpo: Geschichte, Theorie und Praxis der chinesisch-japanischen traditionellen Medizin. Tokio: Tsumura Juntendo; 1976.

11. Eberhard U: Kampo - die japanische Phytotherapie. Deutsche Zeitsch für Akupunktur 2004, 2(47):21-29.

12. Eberhard U: Leitfaden Kampo-Medizin. München: Urban \& Fischer bei Elsevier; 2003.

13. Lock M: The organization and practice of East Asian medicine in Japan: continuity and change. Soc Sci Med 1980, 14B(4):245-253.

14. Fujiwara K, Imanishi J, Watanabe S, Ozasa K, Sakurada K: Changes in attitudes of Japanese doctors toward complementary and alternative medicine: comparison of surveys in 1999 and 2005 in Kyoto. eCAM 2011. doi:10.1093/ecam/nep040.

15. Motoo Y, Arai I, Hyodo I, Tsutani K: Current status of kampo (Japanese herbal) medicines in Japanese clinical practice guidelines. Compl Ther Med 2009, 17(3):147-154.

16. Reißenweber H: Japanische Phytotherapie (Kampo) und ihr Stellenwert in der modernen Medizin. Z Phytother 2002, 23(5):242-246.

17. Kono T, Kanematsu T, Kitajima M: Exodus of kampo, traditional Japanese medicine, from the complementary and alternative medicines: is it time yet? Surgery 2009, 146(5):837-840.

18. Teramoto S: Doctors' attitudes to complementary medicine. Lancet 2000, 355(9202):501-502.

19. Ikarashi N, Shimura A, Takezawa T, Muto A, Toda T, Ito K, Kimura T, Akiba T, Irie Y, Watanabe K, Fukuzawa M, Ishii H, Watanabe K, Sugiyama K: Survey of the use of kampo medicines at kampo clinic l: combined use with Western drugs [Article in Japanese]. Jpn HIth Care Sci 2007, 33(4):353-358.

20. Ikarashi N, Ito K, Kimura T, Akiba T, Yoshifumi I, Watanabe K, Fukuzawa M, Hirokazu I, Watanabe K, Sugiyama K: Survey of the use of kampo medicine at the kampo clinic: patients perceptions and compliance regarding kampo medicines [Article in Japanese]. Kampo Med 2009, 60(4):435-442

21. Matsuoka K, Fukunaga S: Significance and usefulness of Japanese oriental (kampo) medicine in a general hospital [Article in Japanese]. Jpn J Orient Med 1995, 45(3):633-641.

22. Nakano Y, Arai S, Sato H, Shirota F: The level of awareness concerning kampo among out-patients [Article in Japanese]. Jpn J Orient Med 1995, 46(1):121-126.

23. Lock M: East Asian medicine in urban Japan. Berkeley: University of California Press; 1980.

24. Ohnuki-Tierney E: Illness and culture in contemporary Japan. Cambridge: Cambridge University Press; 1984.

25. Flaherty JH, Takahashi R, Teoh J, Kim Jl, Habib S, Ito M, Matsushita S: Use of alternative therapies in older outpatients in the United States and Japan: prevalence, reporting patterns, and perceived effectiveness. J Gerontol Ser A Biol Sci Med Sci 2001, 56(10):M650-655.

26. Fukuda S, Watanabe E, Ono N, Tsubouchi M, Shirakawa T: Use of complementary and alternative medicine and health problems. Nippon Koshu Eisei Zasshi (Jpn J Publ Health) 2006, 53(4):293-300. 
27. Tokuda Y, Takahashi O, Ohde S, Ogata H, Yanai H, Shimbo T, Fukuhara S, Hinohara S, Fukui T: Health locus of control and use of conventional and alternative care: a cohort study. Br I Gen Pract I Roy Coll Gen Pract 2007, 57(541):643-649.

28. Tsuruoka Y, Tsuruoka K, Kajii E: Education in complementary and alternative medicine in Japanese medical schools: follow-up study, 1999-2004 [Article in Japanese]. 医学教育 Igaku Kyôiku (Educ Med) 2005, 36(5):1999-2004.

29. Hottenbacher L: Utilization of kampo in Japan [Thesis in German]. Berlin: Charité Universitätsmedizin, Institute for Social Medicine, Epidemiology and Health Economics: Thesis; 2011

30. Furnham A, Forey J: The attitudes, behaviors and beliefs of patients of conventional vs. complementary (alternative) medicine. J Clin Psychol 1994, 50(3):458-469.

31. Wikimedia commons. http://commons.wikimedia.org/.

32. Sugimoto A, Furnham A: The health beliefs, experiences and personality of Japanese patients seeking orthodox vs. complementary medicine. Complement Ther Med 1999, 7(3):175-182.

33. Konaka H: Increasingly more kampô clinics in university clinics [Article in Japanese]. 日本経済新聞 (Nihon keizai shinbun) 2008, 44030:29. 17 Aug

34. Ikegami N: Japanese health care: low cost through regulated fees. Health Aff (Project Hope) 1991, 10(3):87-109.

35. Ministry of Internal Affairs and Communications: Temperature and precipitation. 2008. http://www.stat.go.jp/data/nenkan/pdf/z01-1.pdf, through http://www.stat.go.jp/english/data/nenkan/1431-01.htm.

36. Ministry of Internal Affairs and Communications: Population of Japan (final report of the 2000 population census). http://www.e-stat.go.jp/SG1/estat/XIsdlE.do? sinfid=000000036AD6, through http://www.e-stat.go.jp/SG1/estat/ListE.do? bid $=000000030587 \&$ cycode $=0$.

37. Ministry of Internal Affairs and Communications: Employment status survey; 2007. www.stat.go.jp/english/data/shugyou/index.htm.

38. Trading economics: Japan unemployment rate. http://www. tradingeconomics.com/japan/unemployment-rate.

39. Harris PE, Cooper KL, Relton C, Thomas KJ: Prevalence of complementary and alternative medicine (CAM) use by the general population: a systematic review and update. Int J Clin Pract 2012, 66(10):924-939.

40. Frass M, StrassI R, Friehs H, Müllner M, Kundi M, Kaye A: Use and acceptance of complementary and alternative medicine among the general population and medical personnel: a systematic review. Ochsner J 2012, 12(1):45-46.

41. Ernst E: Prevalence of use of complementary/alternative medicine: a systematic review. Bull World Health Organ 2000, 78(2):252-257.

42. Naito Y: Hard for many to fight the big chill. http://search.japantimes.co.jp/print/ fl20001227a1.html.

43. Yamada K: Quality of life in patients treated with kampo medicine. J Altern Complement Med 2006, 12(8):799-803.

44. Ariely D: Predictably irrational - the hidden forces that shape our decisions, revised and expanded edn. New York and elsewhere: Harper Perennial; 2009.

\section{Submit your next manuscript to BioMed Central and take full advantage of:}

- Convenient online submission

- Thorough peer review

- No space constraints or color figure charges

- Immediate publication on acceptance

- Inclusion in PubMed, CAS, Scopus and Google Scholar

- Research which is freely available for redistribution

Submit your manuscript at www.biomedcentral.com/submit
Ciomed Central 